\title{
COMPARISON OF MICROSTRIP PATCH ANTENNAS OPERATED ON 2.45GHZ
}

\author{
Michal MÁRTON*, Luboš OVSENÍK*, Ján TURÁN*, Michal ŠPES**, Jakub URBANSKÝ ${ }^{* *}$, Henryk WACHTA*** \\ ${ }^{*}$ Department of Electronics and Multimedia Communications, Faculty of Electrical Engineering and Informatics, \\ Technical University of Košice, Němcovej 32, 04001 Košice, Slovak Republic, tel. +421 55602 4277, e-mail: \\ michal.marton@tuke.sk, lubos.ovsenik@tuke.sk,jan.turan@tuke.sk \\ ** Department of Electrical Power Engineering, Faculty of Electrical Engineering and Informatics, \\ Technical University of Košice, Mäsiarska 74, 04120 Košice, Slovak Republic, tel. +421 556023560 , \\ e-mail: michal.spes@tuke.sk, jakub.urbansky@tuke.sk \\ *** Department of Power Electronics, Power Engineering and Complex Systems, Faculty of Electrical and Computer Engineering \\ Rzeszow University of Technology, W. Pola 2, 35-959 Rzeszow, Poland, Tel.: +48 17865 1977, e-mail: hwachta@prz.edu.pl
}

\begin{abstract}
Nowadays we are living in the ages of innovations. The expansions of communication systems is unbelievable. Many of devices recent are based on database and cloud systems. They need to be connected with other devices and services provider. Well known types of transmission are radio frequency $(R F)$ and optical systems. They use different access for communication. In case of RF systems is need in/out device proposed to receiving/sending of signals. Now are available the many of types of antennas. They are divided by purpose, shape, material, value of radiated power, gain and price. For each purpose is appropriate different type of antenna. The low cost type of antenna is microstrip patch antenna. They are represented by different shapes and materials. Microstrip patch antenna contains the layer of substrate placed between two conduct layers. Parameters of antenna could be affected by change of relative permittivity of substrate. Nowadays are available many of high frequency materials with low value of relative permittivity. The point of this paper is comparison of two types of microstrip patch antennas witch different shapes of radiation patch.
\end{abstract}

Keywords: Ansoft HFSS, microstrip antenna, radiation

\section{INTRODUCTION}

Microstrip patch antennas in recent years expanded in many of different areas. This type of antennas is very popular because their implementation costs are too low in comparison with other antennas. They are characterized by wide angle of radiation, low level of gain and difficulty of impedance matching for case of using microstrip array. The challenge in design is correct impedance matching and modification of conduct layer used as radiation patch. Appropriate impedance matching combine with implementation cut out of patch allow increase gain of antenna. The key parameter of this type of antenna is also used material. The dielectric constant of substrate also dominantly affect parameters of microstrip patch antenna. This paper is focused on impact of cut out of patch antenna in U shape [1-3].

\section{DESIGN OF REFERENCE PATCH ANTENNA}

On the base of theoretical knowledge was designed reference microstrip patch antenna which is used as base for next optimisation process. The width of patch $W p$ is defined by equation (1). Where $c$ is speed of light, $f_{0}$ is operating frequency and $\varepsilon_{r}$ is dielectric constant.

$$
W p=\frac{c}{2 \cdot f_{0} \sqrt{\frac{\varepsilon_{r}+1}{2}}}
$$

For determination of length of substrate we have to define effective value of dielectric constant $\varepsilon_{\text {reff }}$ in (2)

$$
\varepsilon_{\text {reff }}=\frac{\varepsilon_{r}+1}{2}+\frac{\varepsilon_{r}-1}{2}\left(1+12 \frac{h}{W}\right)^{-1 / 2},
$$

where $h$ is thickness of substrate and substrate width $W$. Then the effective length $L_{\text {eff }}$ is defined as

$$
L_{\text {eff }}=\frac{c}{2 f_{0} \sqrt{\varepsilon_{r e f f}}} .
$$

Using effective length from (3) could be defined value length of edging $\Delta L$

$$
\Delta L=0,412 h \frac{\left(\varepsilon_{\text {reff }}+0,3\right)\left(\frac{W}{h}+0,264\right)}{\left(\varepsilon_{\text {reff }}-0,258\right)\left(\frac{W}{h}-0,8\right)},
$$

where $h$ represents height of substrate. Finally the length of patch is defined by (5).

$L p=L_{e f f}-2 \Delta L$

On the base on equations (1-5) were obtained of reference microstrip patch antenna. These parameters are defined in Table 1. Material of dielectric substrate is from Rogers Company denote as RO4350 with smaller value of dielectric constant in comparison with standard PCB (Printed Circuit Board) material FR04 [4-7].

Table 1 Parameters of designed microstrip patch antenna

\begin{tabular}{|l|c|}
\hline \multicolumn{1}{|c|}{ Parameter } & Describe \\
\hline Frequency & $2.45 \mathrm{GHz}$ \\
\hline Substrate & Rogers RO4350 \\
\hline Relative permittivity & $\varepsilon_{\mathrm{r}}=3.66$ \\
\hline Dimension of substrate & $100 \times 90 \times 6 \mathrm{~mm}$ \\
\hline Dimension of patch & $40 \times 30 \times 0.07 \mathrm{~mm}$ \\
\hline
\end{tabular}

Dimensions of substrate are in format " $\mathrm{W} \times \mathrm{L} \times \mathrm{H}$ " (Width $\mathrm{x}$ Length $\mathrm{x}$ Height) and dimensions of patch are in format "Wp x Lp x Hp" (Width x Length x Height). Dimensions of designed reference microstrip patch antenna are in the Fig. 1. Input port is used SMA connector which 
connect two conduct layer placed on both sides of substrate [8-10].

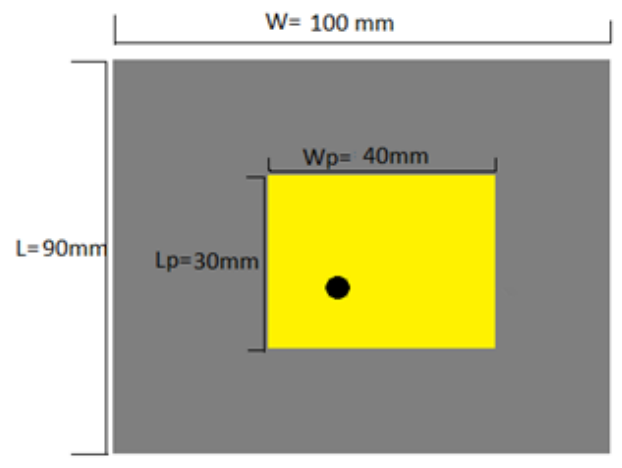

Fig. 1 Dimensions of microstrip patch antenna

In the Fig. 2 could be seen the designed model in development environment of Ansys HFSS software. The boundaries of antenna are represented by semi-transparent block.

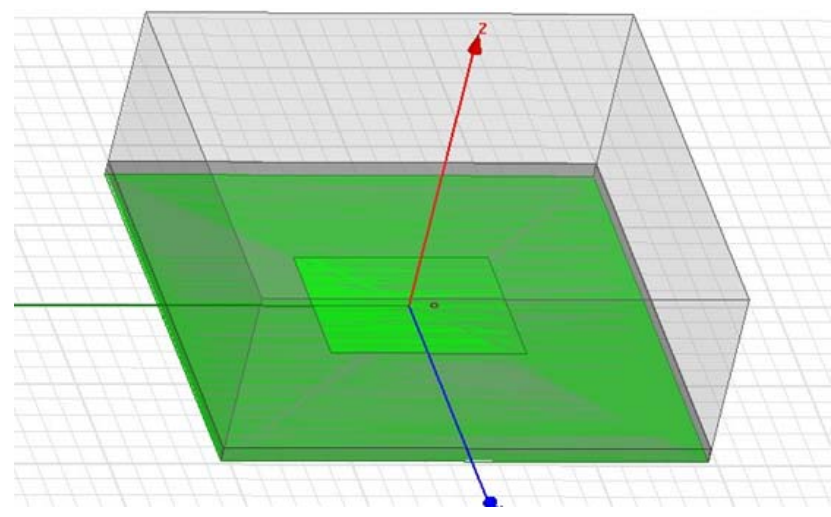

Fig. 2 Designed reference antenna in HFSS Ansys

The main parameter which represents impedance matching and resonance on operating frequency is $\mathrm{S}_{1,1}$ parameter. $S_{1,1}$ parameter represents amount of radiated power on operating frequency. This parameter obtained through simulation of reference microstrip patch antenna without cut out is in the Fig. 3.

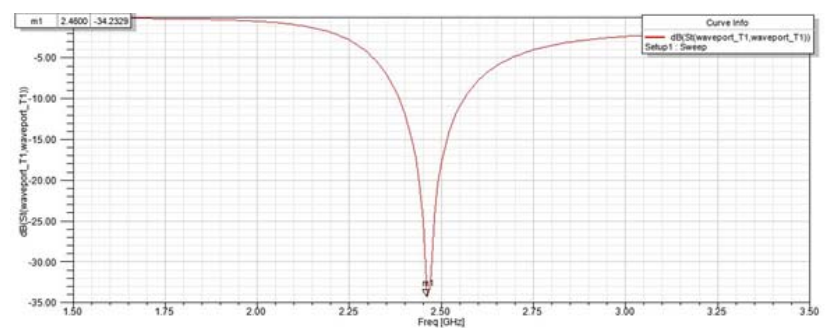

Fig. $3 \mathrm{~S}_{1,1}$ parameter of designed reference antenna in Ansys

The $S_{1,1}$ parameter from Fig. 3 could be determine value of these parameter which correspond with $-34,2329 \mathrm{~dB}$ on operating frequency $2.45 \mathrm{GHz}$.

Total radiation pattern of designed reference antenna placed in 3D shown on operating frequency $2.45 \mathrm{GHz}$ could be seen in the Fig. 4. The area with high level of saturation represents the area of maximal radiation.

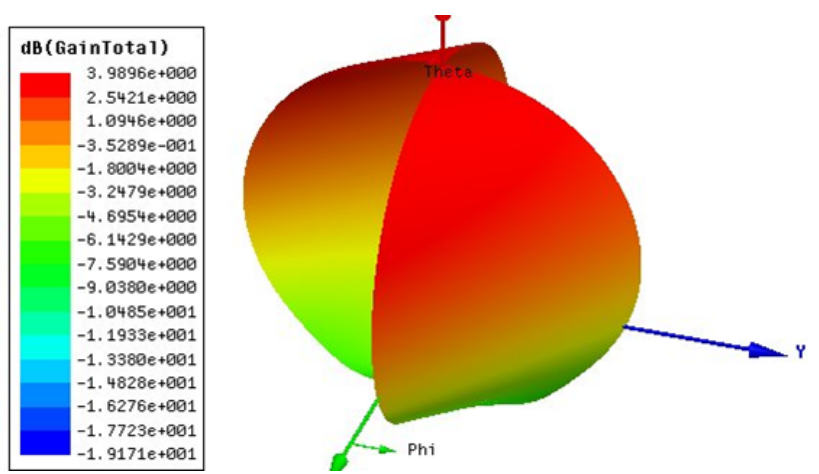

Fig. 4 Radiation pattern of designed reference patch antenna in HFSS Ansys

The radiation pattern of reference antenna in E plane cut which represents cut of electrical plane could be seen in the Fig. 5.

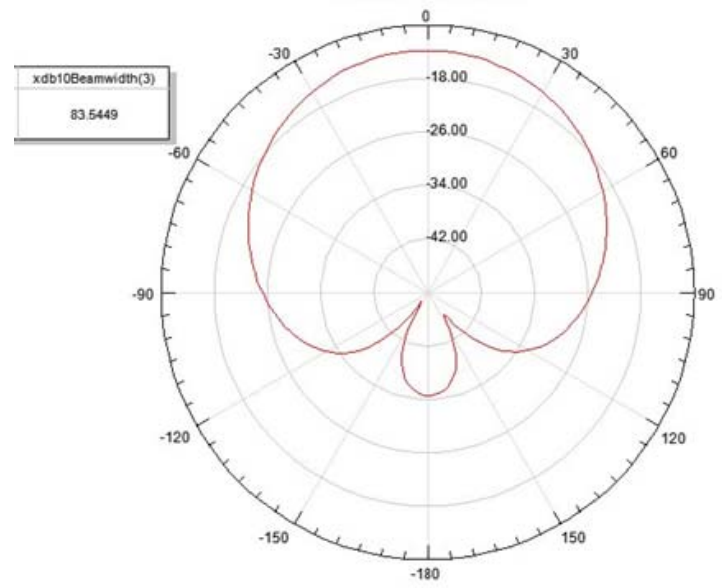

Fig. 5 Angle of radiation in polar coordinates realized for E plane cut

The radiation pattern of reference antenna in $\mathrm{H}$ plane cut which represents cut of electrical plane could be seen in the Fig. 6.

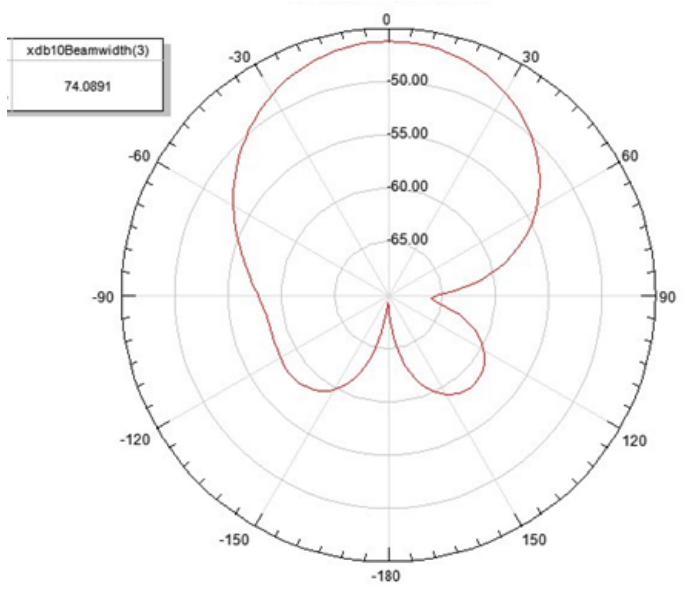

Fig. 6 Angle of radiation in polar coordinates realized for $\mathrm{H}$ plane cut

The parameter which represent maximum value of radiation is radiated power. The obtained value of radiated power from simulation of reference microstrip patch antenna is $1.003 \mathrm{~mW}$ on operating frequency $2.45 \mathrm{GHz}$. 


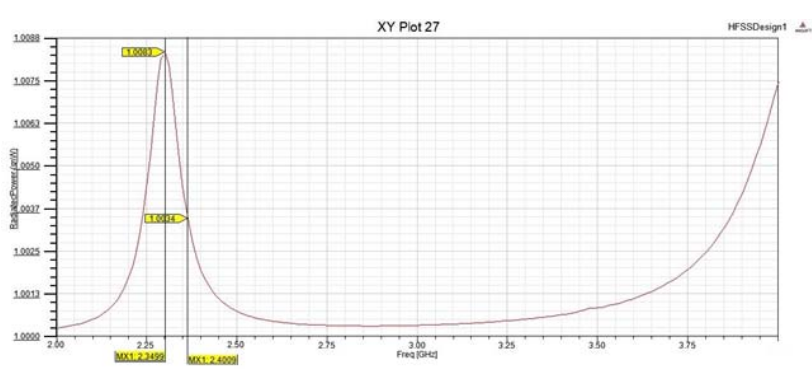

Fig. 7 Maximal radiated power of reference antenna

\section{MICROSTRIP PATCH ANTENNA WITH U-SHAPE CUT}

In this section is realized design of cut out of patch. The dimensions of patch were obtained through optimisation process. These parameters of modified microstrip patch antenna with regards on ensure same operating frequency as reference antenna are in the Table 2 [11-13].

Table 2 Parameters of designed microstrip patch antenna

\begin{tabular}{|l|c|}
\hline \multicolumn{1}{|c|}{ Parameter } & Describe \\
\hline Frequency & $2.45 \mathrm{GHz}$ \\
\hline Substrate & Rogers RO4350 \\
\hline Relative permittivity & $\varepsilon_{\mathrm{r}}=3.66$ \\
\hline Dimension of substrate & $100 \times 90 \times 6 \mathrm{~mm}$ \\
\hline Dimension of patch & $40 \times 30 \times 0.07 \mathrm{~mm}$ \\
\hline
\end{tabular}

Dimensions of substrate are in format "W $x \mathrm{~L} \times \mathrm{H}$ " (Width $\mathrm{x}$ Length $\mathrm{x}$ Height) and dimensions of patch are in format "Wp x Lp x Hp" (Width x Length x Height).

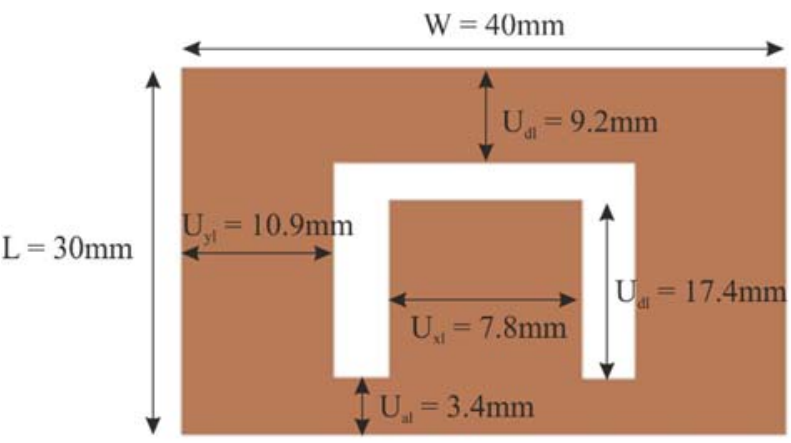

Fig. 8 Dimensions of U-shape cut out of radiation plane of patch

In the Fig. 8 could be seen parameters of patch. The cut out is $U$ shape for increasing the value of gain and expand the radiation angle for ensure the cover of widely area in comparison with reference microstrip patch antenna.

In the Fig. 9 could be seen the designed model in development environment of Ansys HFSS software. The boundaries of antenna are represented by semi-transparent block. The patch is placed on dielectric substrate and under substrate on the bottom layer is conduct grounding layer.

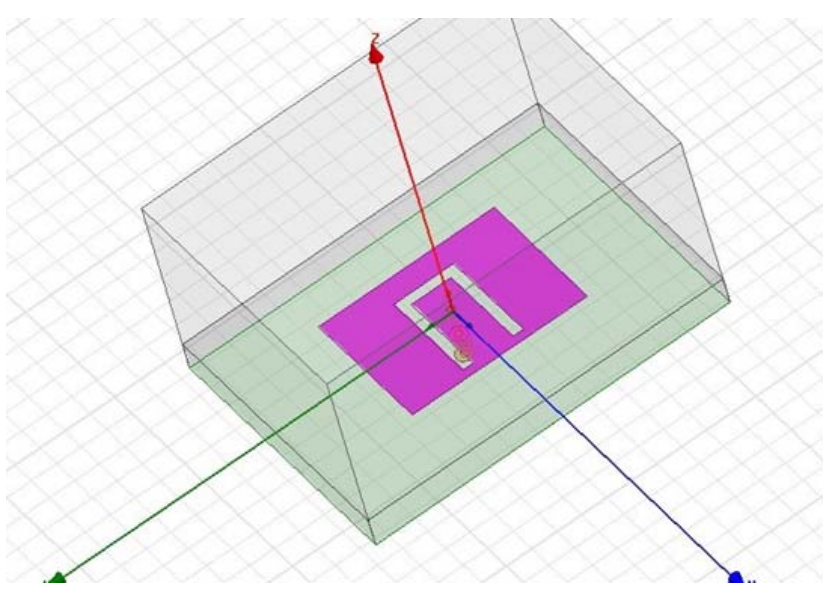

Fig. 9 Design of microstrip patch antenna with U-shape cut out in HFSS Ansys

The $\mathrm{S}_{1,1}$ parameter from Fig. 10 could be determine value of these parameter which correspond with $-33,1316 \mathrm{~dB}$ on operating frequency $2.45 \mathrm{GHz}$.

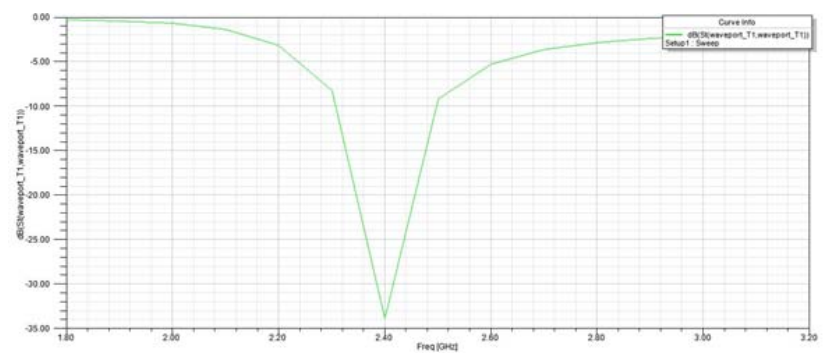

Fig. $10 S_{1,1}$ parameter of antenna with U-shape cut out in Ansys

Total radiation pattern of designed modified antenna placed in 3D shown on operating frequency $2.45 \mathrm{GHz}$ could be seen in the Fig. 11.
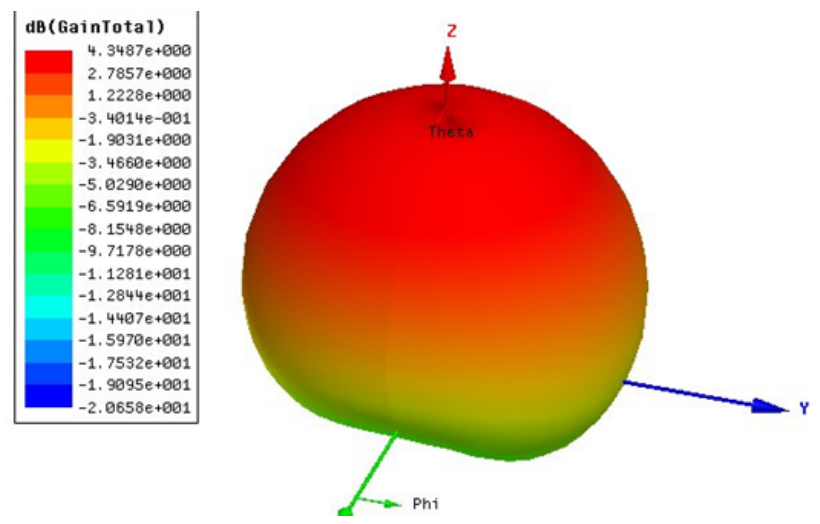

Fig. 11 Radiation pattern of patch antenna with U-shape cut out in HFSS Ansys

The radiation pattern of modified antenna in E plane cut which represents cut of electrical plane could be seen in the Fig. 12. 


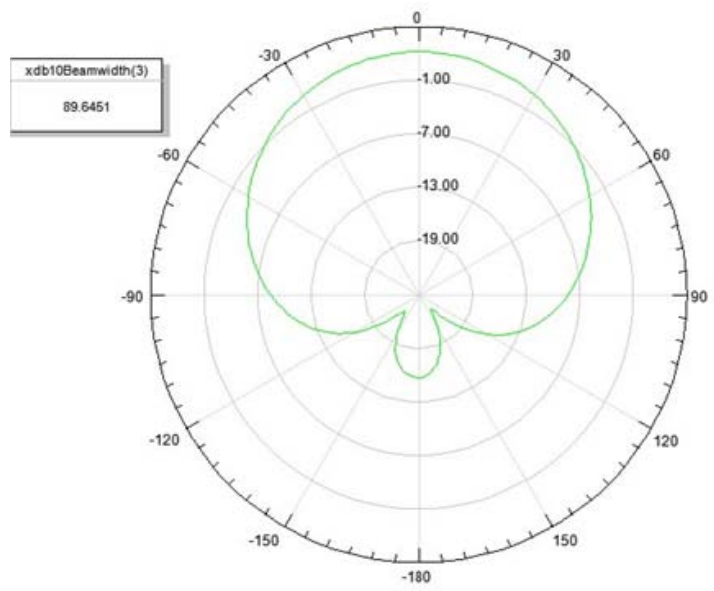

Fig. 12 Angle of radiation in polar coordinates realized for E plane cut out

The radiation pattern of modified antenna in $\mathrm{H}$ plane cut which represents cut of electrical plane could be seen in the Fig. 13.

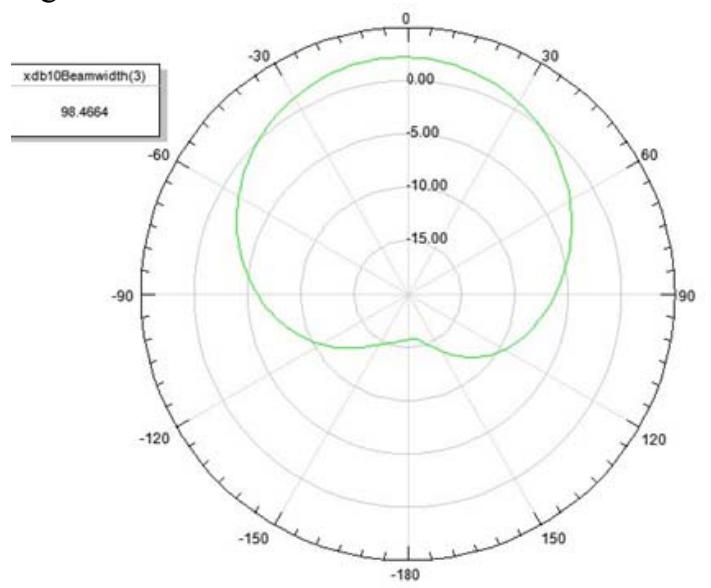

Fig. 13 Angle of radiation in polar coordinates realized for $\mathrm{H}$ plane cut out

The obtained value of radiated power from simulation of reference microstrip patch antenna is $1.003 \mathrm{~mW}$ on operating frequency.

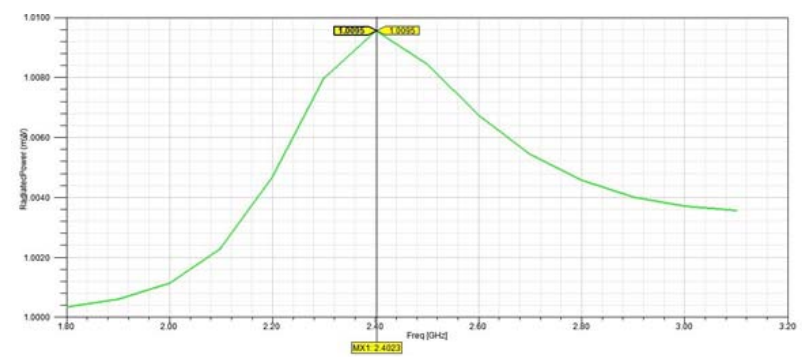

Fig. 14 Maximal radiated power of modified U-shape antenna

In the Fig. 14 could be seen distribution of radiation power which is maximal on operating frequency. The trend line show minimisation of unwanted side radiation which can cause attenuation of other services which operating on frequencies nearby operating frequency of modified antenna.

\section{COMPARISON OF ANTENNAS}

The comparison of these two antennas could be seen in the Table 3. In this table is realized comparison of values of maximal radiated power, total gain, radiation angle in two different cuts.

Table 3 Comparison of reference patch antenna with modified patch antenna

\begin{tabular}{|l|c|c|}
\hline \multicolumn{1}{|c|}{ Parameter } & $\begin{array}{c}\text { Reference } \\
\text { patch } \\
\text { antenna }\end{array}$ & $\begin{array}{c}\text { Patch } \\
\text { antenna with } \\
\text { U-shape cut }\end{array}$ \\
\hline Frequency & $2.45 \mathrm{GHz}$ & $2.45 \mathrm{GHz}$ \\
\hline Gain & $3.99 \mathrm{dBi}$ & $4.35 \mathrm{dBi}$ \\
\hline $\begin{array}{l}\text { Radiation angle } \\
\text { (horizontal cut) }\end{array}$ & $74.09^{\circ}$ & $89.65^{\circ}$ \\
\hline $\begin{array}{l}\text { Radiation angle } \\
\text { (vertical cut) }\end{array}$ & $83.54^{\circ}$ & $98.47^{\circ}$ \\
\hline Radiated power & $1.003 \mathrm{~mW}$ & $1.003 \mathrm{~mW}$ \\
\hline
\end{tabular}

\section{CONCLUSIONS}

The comparison realized in the Table 3 clearly show the differences in parameters of each of antennas. The impact of appropriate implementation of cut out of patch show increasing of parameters of antenna. Total gain of reference antenna obtained 3.99 and total gain of modified antenna obtained 4.35. The modified antenna reach increasing about $0.36 \mathrm{dBi}$. This increasing is not significantly but can be the base step for next optimisation. Higher difference between antennas is in value of radiation angle. The value of angle of radiation of reference antenna in $\mathrm{E}$ plane cut reach $74.09^{\circ}$ and modified antenna obtained $89.65^{\circ}$. Modified antenna reach increasing of radiation angle about $15.61^{\circ}$ in E plane cut. The value of angle of radiation of reference antenna in $\mathrm{H}$ plane cut reach $83.54^{\circ}$ and modified antenna obtained $98.47^{\circ}$. Modified antenna reach increasing of radiation angle about $14.93^{\circ}$ in $\mathrm{H}$ plane cut.

\section{ACKNOWLEDGMENTS}

This work was supported by following research grants: KEGA 023TUKE-4/2017 and the Slovak Research and Development Agency under the contract no. "APVV17-0208 - Resilient mobile networks for content delivery".

\section{REFERENCES}

[1] TÓTH, J. - OVSENÍK, L. - TURÁN. J. MICHAELI, L. - MÁRTON, M.: „Classification prediction analysis of RSSI parameter in hard switching process for $\mathrm{FSO} / \mathrm{RF}$ systems “ In: Measurement, vol. 116, pp. 602-610, 2018

[2] MÁRTON, M. - OVSENÍK, L. - HUSZANÍK, T. ŠPES, M.: Analysis of possibilities for measurement effect of visibility in experimental FSO system, In: Open Computer Science, Vol. 8, no. 1, p. 135-141, ISSN 2299-1093, 2018. 
[3] MÁRTON, M. - OVSENÍK, L. - TURÁN, J. - ŠPES, M.: Design of helix antenna for $2.4 \mathrm{GHz}$ applicable in FSORF hybrid system, In: Mipro 2018, p. 469-472, ISBN 978-953-233-096-0, 2018

[4] CARR, J. - HIPPISLEY, G.: Practical antenna handbook. New York: McGraw-Hill, 2014.

[5] DOUIK, A. - DAHROUJ, H. - AL-NAFFOURI, T. ALOUINI, M.: Hybrid Radio/Free-Space Optical Design for Next Generation Backhaul Systems, In: IEEE Transactions on Communications, vol. 64, no. 6, pp. 2563-2577, 2016.

[6] OVSENÍK, L. - TURÁN, J.: Elektromagnetické vlny a antény (Vybrané prednášky), 1. vyd., Košice:TU, 2017, 339s.,ISBN978-80-553-3156-0.

[7] ORFANIDIS, S. J.: Electromagnetic Waves and Antennas, Rutgers University, 2008, 1021 s., ISBN 978-0130938558.

[8] RATHI V. - PANWAR, V.: Electromagnetic Interference Shielding Analysis of Conducting Composites in Near- and Far-Field Region, IEEE Transactions on Electromagnetic Compatibility, vol. 60, no. 6, pp. 1795-1801, 2018.

[9] GRADONI, G. - RAMAPRIYA, D. - CREAGH, S. - TANNER, G. - BAHARUDDIN, M. - NASSER, H. - SMARTT, C. - TOMAS, D. Near-Field Scanning and Propagation of Correlated LowFrequency Radiated Emissions, IEEE Transactions on Electromagnetic Compatibility, vol. 60, no. 6, pp. 2045-2048, 2018.

[10] HAPP, F. - BURNS, H. - GRONWALD, F.: Application of Huygens' Principle for the Fast Calculation of Field Penetration Through Aperture Arrays", IEEE Transactions on Electromagnetic Compatibility, vol. 60, no. 6, pp. 2025-2028, 2018.

[11] PLAZA, B. - RAMAJO, O. - LOPÉZ, D. POYATOS, D. - ESCOT, D.: Assessment of FEM simulations in EMC test setups for small aeronautical platforms", Journal of Electromagnetic Waves and Applications, vol. 32, no. 17, pp. 2228-2245, 2018.

[12] SU, D. - XIE, S. - CHEN, A. - SHANG, X. - ZHU, K. - XU, H.: Basic Emission Waveform Theory: A Novel Interpretation and Source Identification Method for Electromagnetic Emission of Complex Systems, IEEE Transactions on Electromagnetic Compatibility, vol. 60, no. 5, pp. 1330-1339, 2018.

[13] MIKOLAJCZYK, J. - RUTECKA, B. - SZABRA, D. - WOJTAS, J. - ZAWADZKI, Z. - BIELECKI, Z.: Infrared-radio wireless communication system, 2018 22nd International Microwave and Radar Conference (MIKON), 2018.
Received September 3, 2019, accepted November 12, 2019

\section{BIOGRAPHIES}

Michal Márton (Ing.) received Ing. (MSc.) degree in 2016 at Department of Electronics and Multimedia Telecommunications, Faculty of Electrical Engineering and Informatics of Technical University of Košice. Since September 2016 he has been at University of Technology, Košice as $\mathrm{PhD}$. student. His research interests include optical fiber gyroscopic systems and optical communication systems.

Luboš Ovseník (doc., Ing., PhD.) received Ing. (MSc.) degree in radioelectronics from the University of Technology, Košice, in 1990. He received PhD. degree in electronics from University of Technology, Košice, Slovakia, in 2002. Since February 1997, he has been at the University of Technology, Košice as Associate Professor for electronics and information technology. His general research interests include optoelectronic, digital signal processing, photonics, fiber optic communications and fiber optic sensors.

Ján Turán (Dr.h.c., prof., RNDr., Ing., DrSc.) received Ing. (MSc.) degree in physical engineering with honours from the Czech Technical University, Prague, Czech Republic, in 1974, and RNDr. (MSc.) degree in experimental physics with honours from Charles University, Prague, Czech Republic, in 1980. He received a CSc. (PhD.) and DrSc. degrees in radioelectronics from University of Technology, Košice, Slovakia, in 1983, and 1992, respectively. Since March 1979, he has been at the University of Technology, Košice as Professor for electronics and information technology. His research interests include digital signal processing and fiber optics, communication and sensing.

Michal Špes (Ing., PhD.) was born in 1991. In 2015 graduated $(\mathrm{MSc})$ at the department of electric power engineering. In 2019 graduated (PhD.) at the department of electric power engineering. At present is a project manager. He received a master degree in electric power engineering on subject evaluation of generator exciting outage. His scientific research is mainly focused on research of powerline ampacity system.

Jakub Urbanský (Ing.) was born in 1991. In 2017 graduated (MSc) at the Department of Electrical Power Engineering on the Faculty of Electrical Engineering and Informatics at Technical University in Košice. At present is a Ph.D. student in the Department of Electrical Power Engineering on the Faculty of Electrical Engineering and Informatics at Technical University in Košice. He received a master degree in electric power engineering on subject of the integration of electric vehicle into the electrical power distribution, using the vehicles-to-grid (V2G) technology. His scientific research is mainly focused on research of renewable energy sources. 
Henryk Wachta was born in 1964 in Przemysl, Poland. In 1993 he graduated (MSc) at the Department of Power Electronics and Power Engineering, Faculty of Electrical and Computer Engineering, Rzeszow University of Technology. He defended his $\mathrm{PhD}$. in the field of lighting technology in 2004 at the Warsaw University of
Technology. Since 2004 he is lecturer at the Department of Power Electronics, Power Engineering and Complex Systems at the Rzeszow University of Technology. His scientific research is construction of luminaires and luminaires work in the electrical installation. 